\title{
A Case Report The Understanding of Bioethics: Truth-Telling to Patients of Cancer in Pakistani Perspective
}

\section{Amir Abdullah*}

Northwest Institute of Health Sciences, Peshawar, KPK, Pakistan

*Corresponding author: Amir Abdullah, Assistant Professor, Northwest Institute of Health Sciences, Peshawar, KPK, Pakistan; E-mail: amir.abdullah@nwihs.edu.pk

Received date: August 22, 2014; Accepted date: June 22, 2015; Published date: June 26, 2015

Copyright: (C2015 Amir Abdullah. This is an open-access article distributed under the terms of the Creative Commons Attribution License, which permits unrestricted use, distribution, and reproduction in any medium, provided the original author and source are credited.

\begin{abstract}
Regardless of advancement in the health care profession, cancer is the leading cause of death. After diagnosing the cancer patient, it is difficult for health care professionals to tell the truth or not. A successful relationship between patients and health care providers depends on the establishment of trust, which is strongly connected with communication based on truth. According to utilitarian argument, it is claimed that health professionals must do something which will produce more relief than anything else that it would render. In utilitarianism moral theory, health professionals will hold morally some right actions which will maximize utility, happiness, welfare and well-being. According to Kant, the consequences are not sufficient for making judgment, and informed consent of disease and treatment must be shared with the patient or family members to maintain the dignity. The doctor needs to minimize his/her personal assumptions in treatment and prognosis.
\end{abstract}

\section{Key words:}

Truth; Trust; Autonomy; Beneficence; Non-Malfeasance; Justice; Rights; Dignity and decision.

\section{Introduction}

Regardless of advancement in the health care profession, cancer is the leading cause of death. After diagnosing the cancer patient, it is difficult for health care professional to tell the truth or not to the patients. In clinical practice the questions include not only 'whether' but 'when', 'how' and 'how much' to tell patients about their diagnosis, treatment choices, cost, and possible prognosis. These types of questions create confusion in the medical profession, especially when they try to follow the principles of bio-medical ethics.

\section{Critical incident which raised significant ethical issues}

During clinical experience, a situation was observed, which raised a significant ethical issue. A 32 year old male patient was referred to the tertiary care hospital with uncontrolled fever, headache and fatigue. After complete investigation, he was diagnosed with non-Hodgkin lymphoma stage IV; extensive spreading of the disease outside the lymph systems. The patient was married and was the father of two children. He belonged to the middle class family with three brothers and four sisters. The health professional explained the situation with the family members that after complete treatment he would be cure from that disease. The patient was not informed about his medical disease and treatment. The health professional did not explain the total cost, survival rate, life expectancy, and complication of chemotherapy with the family members. It is the routine of health professionals in Pakistan with every patient; they are very busy which lead to miscommunication with the patient as well as family.

In the present scenario, the patient was not capable to endure the chemotherapy. After initiating chemotherapy, the patient status became deteriorated and developed pancytopenia and infection.
During third cycle the patient became bed rest and developed bed sores. His brother was the medical student in Russia; he came back because of financial problems. After two to three month family became non-affording, and the health professionals was giving them untruthful assurance that everything would be alright. Due to infection and bleeding the patient was intubated which cost eighty thousand Pakistan rupees $(800 \$)$ daily. The patient was in severe pancytopenia, and started gastro intestinal bleeding. He was transfused 20 units of packed red blood cells (PRBC) and 43 units' platelets and fresh frozen plasma (FFPs). Many procedures were performed and the outcome was nothing. After ten days, the health professionals explained that they could not do anything; the patient was in last stage of cancer. It was decided by the medical team to extubate the patient: the patient cancer had spread in many organs. His brother became aggressive and asked from the medical team that if the patient was in last stage, had he explained all those things to his family. We arranged money and decided to start treatment because of your untruthful assurance. It is like to spend huge money to push our patient into this miserable life. In Pakistan, the people are not aware from their legal rights. The system fully supports the medical as a dominant profession in the society. Therefore, these types of ethical issues are very common [1].

\section{Main ethical issues}

The incident shows many ethical issues in health profession. In the case of health professionals, the question arises whether he has the authority to make decisions for others. He was aware from the consequences and did not explain it to the family and patient. The goal of providing optimal health care is to explain and provide detail information to the patient and family about treatment to maintain autonomy, beneficence, non-maleficence, and justice. A successful relationship between patients and health care providers depends on the establishment of trust, which is strongly connected with truthful communication. It also arises from the incident that people trust the medical profession for human care and cure. When they experienced such situations, they lose trust forever. The four principles of 
Beauchamp and Childress were also not followed, which is to maintain autonomy, beneficence, non-maleficence, and justice.

The patient was diagnosed with $4^{\text {th }}$ stage of non-Hodgkin lymphoma in which the prognoses was very poor, and most of the family finances were spent for nothing. Family will face the finances problem for whole life. It means that the principles of Utilitarianism and Consequentialism were also not followed because the prognosis of diseases was very poor and they spent the scarce finances just for the sake of nothing.

\section{Discussion on the Basis Ethical Approaches}

\section{The health professional and telling truth}

After complete assessment, it is the duty of health professional to tell the truth that the patient is suffering from serious disease which is probably or possibly has low chance of recovery. The treatment choice is very expensive and the chance of recovery is very low. It is also the duty of doctor to explain the complication of chemotherapy with the family as well as with the patient. After giving complete information then let them decide for their treatment choice. In the case of health professionals, they do not have the authority to take the decision for the patient. The health professionals need to explain and provide detail information and permit the patient and family to decide for themselves. Family and patients should be given the freedom to make their own choices, and satisfaction regarding their treatment choices. Thus individuals normally have rights to make decision affecting the course of their lives. The health professionals are bond to their duty and do whatever is best for the patients. The health professionals need to implement multi-dimensional approach for the patient and family.

In that case, mentioned above, the health professionals were not attentive from the consequences of the family financial issues. They were trying to give optimal health care and increase the life expectancy. It was the possibility that if, the health professionals would have explained detail information about the disease: the family would have chosen the best option for the treatment. It was also the rights of a patient and family to be told the truth about his condition. They had also the rights to refuse or accept the treatment. However, there are other frequent circumstances in which patient and family can decide for the best option of treatment. They are the people who will face the consequences after worsen the condition.

In this case, health professionals have the duty to deliver the complete information according to his cultural level and abilities to understand. This information will base on the diagnosis, prognosis, therapeutic perspective, and their consequences. Each query requested by the patient and family has to be acknowledged and to be answered undoubtedly. The health professionals need to evaluate the effectiveness of treatment and prognosis and explain it to the family on time. If, they would communicate with the family for possible outcome and complication then the case would be different. Furthermore, if the family was explained on time they would be in good position to take the decision for the patient. By clarifying diagnosis, prognosis, and treatment alternatives to the patient, it was generating the basis for autonomy, beneficence, non-maleficence, and justice.

\section{Beauchamp and childress principles}

In clinical situations, health professionals will respect family and patient autonomy, where the patient and family is given the freedom of choice regarding treatment, for example, in deciding whether they wish to be intubated during critical situation or not. Due to poor prognosis and financial issues, it is the probability that they may refuse the selected treatment option. If, a patient lacks capability for such a decision and there is a need of advance directive, then the family member who is accountable for treatment can take the decision [2]. By following this, we can maintain the Beauchamp and Childress principles as well as the paternalistic approach. In that case, the health professionals did not follow the bioethics principles and took all the decision by them, which will affect their family for the whole life. Autonomy is an agreement to respect another's right to self-determine a course of action; support of independent decision making [3].

In this case, the health professionals administered the chemotherapy to control the cancer and increase life expectancy. It was an act of beneficence to treat the patient up to optimal level of health. On the other hand, health professionals were aware from the complication and cost but they did not explain all those information to the family. It was an act of maleficence to the family and patient. The patient developed complications and was intubated without proper explanation. The family was not aware from the benefits and risk associated with treatment. It is the duty of medical professionals to obtain informed consent for the chemotherapy and intubation and explain the benefits and risks to prevent harm and maximize benefits. In developing countries specially, in Pakistan, the families and patients are not aware from their rights and the doctors are using their authority for treatment [4]. It is clear from the literature that the prognosis of cancer is last stage is very poor [5]. Therefore, it is necessary to explain everything with the family and patient to decline confusion for further decision.

In this situation, the health professionals are dealing with the autonomy of patient and family. If, they will maintain his autonomy and do not explain the entire possible situation may cause harm to the patient as well to the family. Actually health care providers are negotiating between his autonomy with the patient and family autonomy. In this scenario, the important point is to prevent unnecessary problem for the patient and family, and it will be a paternalistic approach over autonomy. The practice of beneficence and non-beneficence was challenge by the respect of autonomy. Thus, the old-style Hippocratic moral requirement of bio-medical ethics is to provide benefits to patients with minimal harm - that is, beneficence with non-maleficence [6].

\section{Utilitarianism, Kantian ethics}

According to utilitarian argument, we claim that we must do something which will produce more happiness than anything else would. Furthermore, in utilitarianism moral theory we will hold morally right action which will maximize utility, happiness, welfare and well-being [7]. Utilitarianism is totally against from egoism which only cares about his own welfare and happiness. In the above case, the health care providers are thinking about their welfare and development of the hospital. They were aware from the complication and compensations of ventilator for the patients. Beside, these information and investigation they decided chemotherapy and intubation which led the patient to complication. On the other hand, the family will face the financial problem for long period because in Pakistan $80 \%$ of the population utilized private treatment facilities [8]. It shows clearly that the utility of finances were not utilized properly.

In utilitarian, health professional will perform those acts which will lead to good consequences to maximize happiness and welfare. It will 
be good to explain all the possible consequences with family because they knew the entire possible outcome. The health professional are thinking only on one dimension and the rest of the consequences were hidden from them. Therefore, health professionals need to involve patient and family during health care plan. By doing this, we can prevent from the maleficence and the family will be ready for any worsen situation. They will be satisfied from the health professional because every step would be taken with mutual decision. Health professionals need to utilize the resources to provide the optimal care and enhance the life expectancy of greater number of people, as opposed to expending maximum resources on a single critically ill person who is difficult to survive [9-12].

\section{Conclusion}

In medical ethics, most of the concepts and principles support the patient and family rights for treatment and decision making. The main goal of health treatments is to maintain optimal health of patient, family, and community. Therefore, it is the duty of health professionals to explain every treatment and procedure to the patient and enable them for their future decision. According to Kant, the consequences are not sufficient for making judgment, and informed consent of disease and treatment must be share with the patient or family members to maintain the dignity. The health professionals need to minimize their personal assumptions in treatment and prognosis.

From the whole discussion, it is clear that the health professional should disclose the information about diagnosis, prognosis, and possible complication of treatment to the patient and family, and involve them with responsibility, care, and circumspection in decision making. It might be sensible to explain the possible outcome and worsen conditions immediately in a very poor prognosis, for the benefit of the patient and family, in order to maintain the right of the patient and family to decide about their future. A successful relationship between patients and health professionals depend on the establishment of trust, which is strongly connected with truthful communication.

\section{References}

1. Shiraz B, Shamim MS, Shamim, MS, Ahmed A (2005) Medical ethics in surgical wards: knowledge, attitude and practice of surgical team members in Karachi. Indian J Med Ethics 2: 94-96.

2. Morrison LJ, Kierzek G, Diekema DS, Sayre MR, Silvers SM, (2010) Part 3: Ethics 2010 American Heart Association Guidelines for Cardiopulmonary Resuscitation and Emergency Cardiovascular Care. Circulation, 122: S665-S675.

3. Beauchamp TL, Childress JF (2009) Principles of biomedical ethics New York, NY 6: 38-39.

4. Pakenham WN, Bukachi F (2009) Information needs of health care workers in developing countries: a literature review with a focus on Africa. Human resources for health 7: 30 .

5. Innes S, Payne S (2008) Advanced cancer patient's prognostic information preferences: a review Palliative Medicine. Palliat Med 23: 29-39.

6. Gillon R (1994) Medical ethics: four principles plus attention to scope. BMJ 309: 184 .

7. Glasgow J (2007) Kant's conception of humanity. Journal of the History of Philosophy 45: 291-308.

8. Aslam L, Abdullah A, Ayub R (2014) Analysis of Pakistan and Iran Health Care Delivery System. International Journal of Innovative Research and Development 3: 308-312.

9. Draper H, Sorell T (2002) Patient's responsibilities in medical ethics. Bioethics 16: 335-352.

10. Longtin Y, Sax H, Leape LL, Sheridan SE, Donaldson L,et al. (2010) Patient participation: current knowledge and applicability to patient safety. In Mayo Clinic Proceedings 85: 53-62.

11. Rachels J, Rachels S (2003) The right thing to do: Basic readings in moral philosophy. McGraw-Hill.

12. Surbone A (1999). Truth telling to the patient. Virtual Mentor 1: 52-62. 